\section{Ocorrência de cães errantes soropositivos para Leptospira spp. na Cidade de Itapema, Santa Catarina, Brasil}

\author{
Occurrence of Leptospira spp. soropositive \\ stray dogs in Itapema, Santa Catarina, Brazil
}

Renê Darela Blazius 1,3

Pedro Roosevelt Torres Romão ${ }^{1}$

Ester Meire Costa Gouveia Blazius 2 Onilda Santos da Silva 1,3

\section{Introdução}

${ }^{1}$ Laboratório de Imunoparasitologia, Universidade do Sul de Santa Catarina, Tubarão, Brasil.

2 Biotério Central, Universidade do Sul de Santa Catarina.

Tubarão, Brasil.

3 Mestrado em Saúde Coletiva, Universidade

do Sul de Santa Catarina, Tubarão, Brasil.

Correspondência O. S. Silva

Laboratório de

Imunoparasitologia, Universidade do Sul

de Santa Catarina.

Av. José Acácio Moreira 787

Tubarão, $S C$

88704-900, Brasil.

silva-os@unisul.br

\begin{abstract}
This study aimed to verify Leptospira spp.
Abstract serovar infections in stray dogs in Itapema, Santa Catarina, Brazil. Serum samples were collected from 590 stray dogs and tested against 25 Leptospira spp. serovars using the microscopic agglutination test. Prevalence of anti-leptospiral antibodies against one or more serovars was 10.5\%. The most frequent serovar was pyrogenes, positive in 26 (18.0\%) samples, followed by canicola with 20 (13.8\%) and icterohaemorragiae and copenhageni with 18 (12.5\%, with antibody titers from 1:100 to 1:3,200). Significant prevalence (10.4 to $11.1 \%$ ) was also detected against serovars castellonis, butembo, and grippothyphosa.
\end{abstract}

Leptospirosis; Dogs; Infection
A leptospirose é uma das zoonoses mais difundidas no mundo. No Brasil, sua incidência aumenta principalmente no verão em decorrência de chuvas e alagamentos de áreas urbanas, sendo comum a ocorrência de surtos epidêmicos em épocas de maior precipitação pluviométrica ${ }^{1}$. No período de 1980 a 2003 foram confirmados 53.354 casos de leptospirose no país (Secretaria de Vigilância em Saúde, Ministério da Saúde. Distribuição de Casos Confirmados por Unidade Federada de 1980 a 2003. http: / / dtr2001.saude.gov.br/svs/epi/situacao_doencas/planilhas_doencas.htm, acessado em 02/ Mar/2005). Entre os anos de 1994 e 2003 foram registrados em média 3.324 casos/ano, sendo a taxa média de letalidade anual de cerca de 10,0\% 2. No Estado de Santa Catarina, no período de 1980 a 2003, foram confirmados 2.523 casos de leptospirose.

A leptospirose acomete animais domésticos, silvestres e o homem. Tanto animais domésticos como silvestres podem se tornar portadores e contribuir para a disseminação das leptospiras na natureza ${ }^{3}$. A transmissão ocorre por meio do contato com água contaminada por espiroquetas que são eliminadas na urina de ratos, gatos, cães e outros animais 4 . Animais que vivem em áreas urbanas, cujas condições sanitárias e de infra-estrutura são precárias, junto a lixões, esgotos a céu aberto, depósitos 
de materiais descartados, restos alimentares e promiscuidade com outras espécies animais, se constituem particularmente em população de risco ${ }^{5}$. Os cães podem adquirir a infecção pela convivência com outros cães contaminados, bem como ratos que urinam em áreas comuns. Esses animais são considerados a principal fonte da leptospirose humana em áreas urbanas, pois vivem em estreito contato com o homem e podem eliminar leptospiras vivas através da urina durante vários meses, mesmo sem apresentar nenhum sinal clínico característico 6 . A sobrevivência de leptospiras no ambiente depende principalmente de umidade, temperatura elevada e pH levemente alcalino 7 . Desse modo, a prevalência de leptospirose depende de um animal portador que é o disseminador, da contaminação e sobrevivência do agente no ambiente e do contato de indivíduos susceptíveis com o agente. Vários animais podem ser hospedeiros e, cada sorovar tem um ou mais hospedeiros com diferentes níveis de adaptação. A persistência de focos de leptospirose se deve aos animais infectados, convalescentes e assintomáticos, que servem como fonte contínua de contaminação ambiental 8 .

Itapema é um balneário ao nordeste do Estado de Santa Catarina, cuja principal atividade econômica é o turismo. No verão, a população do município (aproximadamente 26.500) aumenta para 120 mil habitantes (Governo do Estado de Santa Catarina. Municípios de Santa Catarina: Itapema. http://www.sc.gov.br/conteudo/municipios/frametsetmunicipios.htm, acessado em 02/Mar/2005). Nesse período, turistas de várias regiões do Brasil visitam esse local para apreciar suas belezas naturais e águas cristalinas. No balneário há um grande número de cães soltos nas ruas, praças e praias. Estes animais representam risco potencial à saúde do homem, podendo transmitir várias zoonoses, dentre estas, a leptospirose.

Em Santa Catarina não há relatos na literatura sobre os sorovares de leptospiras que circulam nas espécies caninas, ou mesmo em animais silvestres. Entretanto, dados referindo-se a suínos e eqüinos são citados por Favaro et al. 9 e Santa-Rosa et al. 10. Um estudo que busque determinar a soroprevalência de Leptospira spp. na população canina tem grande importância para o conhecimento dos sorovares circulantes nessa região do Brasil. Assim, o objetivo deste estudo foi detectar anticorpos contra Leptospira spp. e os sorovares mais freqüentes em cães errantes do balneário de Itapema.

\section{Material e métodos}

\section{Amostras}

Foram utilizadas amostras séricas de 590 cães de rua, da zona urbana do Município de Itapema, que foram capturados pela vigilância sanitária da cidade no período de agosto de 2000 a maio de 2005. De cada animal foi colhida uma amostra de $10 \mathrm{ml}$ de sangue.

\section{Coleta e processamento das amostras}

Para identificação dos sorovares utilizou-se a técnica de soroaglutinação microscópica (SAM) 11, empregando-se um total de 25 antígenos vivos, representados por icterohaemorragiae, $c a-$ nicola, ballum, andamana, patoc, australis, grippothyphosa, panama, hardjo, pomona, pyrogenes, wolffi, bataviae, bratislava, butembo, javanica, hebdomadis, autumnalis, castellonis, cellendoni, copenhageni, cynopteri, djasiman, shermani e tarassovi. A triagem foi efetuada na diluição de 1:100 e, quando houve aglutinação, os soros foram titulados em uma série geométrica de diluições de razão dois. O título foi dado como recíproca da maior diluição em que houve $50,0 \%$ de aglutinação das leptospiras.

Os exames foram realizados pelo Laboratório de Análises Clínicas da Universidade do Sul de Santa Catarina (UNISUL) em Tubarão, Santa Catarina.

\section{Resultados}

A soropositividade para leptospirose em cães de rua de Itapema foi de 10,5\%, quando consideradas reações para quaisquer dos sorovares utilizados como antígeno. Das 590 amostras analisadas, $528(89,5 \%)$ foram negativas e 62 $(10,5 \%)$ foram positivas para um ou mais sorovares com títulos iguais ou maiores que 1:100.

Nas amostras positivas, os sorovares mais freqüentes foram: pyrogenes com 26 (18,0\%) amostras positivas e títulos variando de 1:100 a 1:1.600, canicola com $20(13,8 \%)$ amostras positivas e títulos variando entre 1:100 e 1:1.600, icterohaemorragiae e copenhageni com 18 $(12,5 \%)$ amostras positivas e títulos variando de $1: 100$ a $1: 3.200$. Alta soropositividade (10,4$11,1 \%)$ também foi encontrada para os sorovares castellonis, butembo e grippothyphosa. Observa-se que os títulos na sua maioria situamse na faixa de 1:200 a 1:400, sendo que o maior 
título foi de 1:3.200 para o sorovar copenhageni (Tabela 1).

\section{Discussão}

Neste estudo obteve-se soropositividade em $10,5 \%$ dos cães examinados. Esta taxa foi similar àquela obtida por outros pesquisadores (10,0-22,0\%) para a população canina de outras regiões do Brasil 12. Situação semelhante observou-se com relação aos sorovares pyrogenes, grippothyphosa e canicola em relatos de outros autores para amostras séricas de cães no Brasil 12,13,14. Com relação ao sorovar pyrogenes, encontramos cães com taxa de infecção de $18,0 \%$. De acordo com Jouglard \& Brod 6 , o sorovar pyrogenes é considerado acidental em cães.

A prevalência da leptospirose em cães varia consideravelmente entre áreas e entre países, sendo mais elevada em regiões tropicais. Os sorovares mais comumente associados e conhecidos da leptospirose canina clássica são icterohaemorrahagiae e canicola ${ }^{15}$. A freqüência de soroaglutinação encontrada para o sorovar $c a$ nicola em cães de rua de Itapema $(13,8 \%)$ foi semelhante àquela encontrada por Viegas et al. 16 em estudo realizado com cães de rua da cidade de Salvador, Bahia (16,5\%). O sorovar canicola, sendo o segundo mais freqüente neste estudo, alerta para o fato de o cão (principal hos- pedeiro deste sorovar) constituir-se uma importante fonte de infecção para o homem. Nestes animais, este sorovar se aloja no rim, ocorrendo eliminação das bactérias durante longo período. Desse modo, para esse sorovar, o cão, em especial, pode constituir uma importante fonte de infecção humana 17. No homem esse sorovar apresenta elevada prevalência. Em Morón, Cuba, Suárez-Hernández et al. 18 descreveram seis casos de leptospirose, sendo que em quatro casos ocorreu síndrome de meningite asséptica causada pelo sorovar canicola.

Em alguns estudos, as variantes sorológicas copenhageni e icterohaemorragiae foram encontradas em alta freqüência em amostras séricas de cães 19,20. Em nosso estudo a taxa de prevalência para estes sorovares foi de $12,5 \%$. A espécie L. interrogans tem vários sorovares e, no Brasil, o sorovar icterohaemorrahagiae parece ser o mais comum. Em Recife, Salvador e São Paulo este sorovar foi identificado como agente causal em mais de 50,0\% dos casos descritos 21 . Romero et al. 22 verificaram que dos casos de leptospirose diagnosticados na Cidade de São Paulo entre 1969 e 1997, 54,8\% foram positivos para o sorovar icterohaemorrahagiae. Em 1995 foram confirmados 19 casos de leptospirose humana em Belo Horizonte. Neste estudo verificou-se que $38,8 \%$ dos soros apresentaram resultados positivos com títulos mais elevados para os sorovares icterohaemorraha-

Tabela 1

Freqüência da positividade de amostras sorológicas de cães errantes da Cidade de Itapema,

Santa Catarina, Brasil, ao teste de SAM, segundo o sorovar reagente e o título obtido.

\begin{tabular}{|c|c|c|c|c|c|c|c|c|}
\hline \multirow[t]{2}{*}{ Sorovar } & \multicolumn{6}{|c|}{ Títulos } & \multirow[t]{2}{*}{ Total } & \multirow[t]{2}{*}{$\%$} \\
\hline & $1: 100$ & $1: 200$ & $1: 400$ & $1: 800$ & $1: 1.600$ & $1: 3.200$ & & \\
\hline Pyrogenes & 2 & 13 & 5 & 5 & 1 & - & 26 & 18,0 \\
\hline Canicola & 2 & 7 & 8 & 1 & 2 & - & 20 & 13,8 \\
\hline Copenhageni & 1 & 9 & 5 & 2 & - & 1 & 18 & 12,5 \\
\hline Icterohaemorragiae & 5 & 6 & 2 & 2 & 3 & - & 18 & 12,5 \\
\hline Grippothyphosa & 2 & 9 & 4 & 1 & - & - & 16 & 11,1 \\
\hline Butembo & 4 & 6 & 3 & 1 & 1 & - & 15 & 10,4 \\
\hline Castellonis & 1 & 3 & 7 & 2 & 2 & - & 15 & 10,4 \\
\hline Pomona & - & 1 & 2 & - & 1 & - & 4 & 2,7 \\
\hline Hebdomani & 2 & 1 & - & - & - & - & 3 & 2,1 \\
\hline Ballum & 1 & - & 1 & - & 1 & - & 3 & 2,1 \\
\hline Shermani & 1 & 1 & - & - & - & - & 2 & 1,4 \\
\hline Cynopteri & 1 & 1 & - & - & - & - & 2 & 1,4 \\
\hline Andamana & - & 1 & - & - & - & - & 1 & 0,7 \\
\hline Wolffi & - & 1 & - & - & - & - & 1 & 0,7 \\
\hline Total & 22 & 59 & 37 & 14 & 11 & 1 & 144 & 100,0 \\
\hline
\end{tabular}


giae e canicola 23. Em São Paulo, no período de 1986 a 1989, os sorovares mais freqüentemente isolados de pacientes hospitalizados foram o conpenhageni $(77,0 \%)$ e o canicola $(11,1 \%) 16$.

A análise dos resultados dos sorovares de leptospiras revelou a ocorrência de casos de coaglutinação sorológica, em que mais de uma variante apresentou titulação para um mesmo soro, o que é um forte indicativo de reações cruzadas. Títulos considerados baixos, de $100 \mathrm{e}$ 200, podem ser encontrados em amostras de animais convalescentes como título residual de infecção prévia ou em casos de infecção recém-instalada e podem ser significantes em animais não vacinados 17 .

Semestralmente são coletados cerca de cem cães que vivem nas ruas da cidade de Itapema. Como demonstrado, estes animais são fontes potenciais para a disseminação de leptospiras para o ambiente, e conseqüente infecção humana.

A fonte de infecção canina dessa região ainda não é conhecida. De acordo com a Funda- ção Nacional de Saúde, os principais reservatórios da espiroqueta são constituídos pelos roedores sinantrópicos das espécies Rattus norvegicus, Rattus rattus e Mus musculus. Assim, sugere-se que estes animais sejam a fonte mais importante de infecção para cães. É necessário, entretanto, fazer um estudo da fauna local para identificar as possíveis causas de risco para a infecção canina.

A leptospirose possui caráter sazonal, relacionando-se a períodos chuvosos, quando há elevação dos índices pluviométricos e um conseqüente aumento na incidência dos casos da doença 1. Em Santa Catarina, a incidência de chuvas é maior no período de dezembro a janeiro, coincidindo com o período de maior fluxo turístico na região. Os resultados deste estudo demonstram a importância da identificação de cães errantes infectados por Leptospira spp. na Cidade de Itapema, pois podem servir de alerta aos órgãos de saúde pública e à população, para um maior controle desses animais.

\section{Resumo}

O objetivo deste trabalho foi verificar a ocorrência de infecção por Leptospira spp. em cães errantes de Itapema, Santa Catarina, Brasil. As amostras de soro coletadas em 590 cães de rua foram testadas contra 25 sorovares de Leptospira spp. usando-se o teste de soro aglutinação microscópica. A ocorrência de anticorpos antileptospiras para um ou mais sorovares foi de 10,5\%. O sorovar mais freqüente foi pyrogenes com 26 (18,0\%) amostras positivas, seguido pelos sorovares canicola 20 (13,8\%), icterohaemorragiae $e$ copenhageni com 18 (12,5\%), com títulos de anticorpos variando de 1:100 a 1:3.200. Considerável prevalência (10,4$11,1 \%)$ também foi detectada para os sorovares castellonis, butembo $e$ grippothyphosa.

Leptospirose; Cães; Infecção

\section{Colaboradores}

R. D. Blazius participou das seguintes etapas: manejo sanitário dos animais, escolha do tema, montagem das tabelas, procura e revisão das publicações, elaboração do artigo; E. M. C. G. Blazius participou das seguintes etapas: coleta de sangue, obtenção de soro dos animais e manejo sanitário dos animais em quarentena; P. R. T. Romão contribuiu com a escolha do título, revisão da literatura, elaboração do artigo, discussão dos dados e revisão final. O. S. Silva participou da escolha do título, elaboração do resumo e abstract, discussão dos dados e revisão final do texto.

\section{Agradecimentos}

Os autores agradecem ao pessoal do Setor de Imunologia do Laboratório de Análises Clínicas da UNISUL pela realização dos ensaios de soroaglutinação microscópica (SAM). 


\section{Referências}

1. Fundação Nacional de Saúde. Guia de vigilância epidemiológica. Brasília: Fundação Nacional de Saúde; 2002.

2. Ministério da Saúde. Saúde Brasil 2004: uma análise da situação de saúde. Brasília: Ministério da Saúde; 2004.

3. Girio RJS, Pereira FLG, Marchiori Filho M, Mathias LA, Herreira, RCP, Alessi AC, et al. Pesquisa de anticorpos contra Leptospira spp. em animais silvestres e em estado feral da região de Nhecolândia, Mato Grosso do Sul, Brasil: utilização da técnica de imuno-histoquímica para detecção do agente. Ciênc Rural 2004; 34:165-9.

4. Correa MO. Human leptospirosis in Brazil. Int J Zoonoses 1975; 2:1-9.

5. Genovez ME. Leptospirose em cães. Pet Vet 1996; 1:6-9.

6. Jouglard SDD, Brod CS. Leptospirose em cães: prevalência e fatores de risco no meio rural do $\mathrm{Mu}-$ nicípio de Pelotas, RS. Arq Inst Biol 2000; 67:181-5.

7. Karaseva EV, Chernuckha YG, Piskunova LA. Results of studying the time of survival of pathoginic leptospira under natural conditions. J Hyg Epidemiol Microbiol Immunol 1973; 17:339-45.

8. Oliveira SJ, Pires Neto JAS. Aspectos etiológicos e de diagnóstico nas leptospiroses. Revista do Conselho Federal de Medicina Veterinária e Zootecnia 2004; 33:36-46.

9. Favero ACM, Pinheiro SR, Vasconcellos AS, Morais ZM, Ferreira F, Neto JSF. Sorovares de leptospirose predominantes em exames sorológicos de bubalinos, ovinos, caprinos, eqüinos, suínos e cães de diversos estados brasileiros. Ciênc Rural 2002; 32:613-9.

10. Santa-Rosa CA, Silva AS, Giorgi W, Machado A. Isolation of leptospira serotype pomona and brucella suis from swines from the State of Santa Catarina, Brazil. Arq Inst Biol 1973; 40:29-32.

11. Santa-Rosa CA. Diagnóstico laboratorial das leptospiroses. Rev Microbiol 1970; 1:97-107.

12. Alves CJ, Andrade JSL, Vasconcelos SA, Morals, ZM, Azevedo SS, Santos FA. Avaliação dos níveis de aglutininas antileptospira em cães no Município de Patos-PB, Brasil. Rev Bras Ciênc Vet 2000; 7:17-21.

13. Yasuda PH, Santa-Rosa CA, Myers DM. The isolation of leptospires from stray dogs in the city of São Paulo, Brazil. Int J Zoonoses 1980; 7:131-4.
14. Machado RR, Brod CS, Chaffe ABP, Fehlberg MF, Martins LFS, Ludtke CB. Leptospirose canina na região sul do Brasil, ano de 1998. In: Anais do 14oㅡ Congresso Estadual de Medicina Veterinária \& do 3o Congresso de Medicina Veterinária do Cone Sul. Gramado: Sociedade de Veterinária do Rio Grande do Sul; 1999. p. 103.

15. Brihuega B, Hutter E. Incidencia de la leptospirosis em caninos de la ciudad de Buenos Aires. Veterinária Argentina 1994; 11:98-101.

16. Viegas SARA, Tavares CHT, Oliveira EMD, Dias AR, Mendonça FF, Santos MFP. Investigação sorológica para leptospirose em cães errantes na Cidade de Salvador, Bahia. Revista Brasileira de Saúde e Produção Animal 2001; 2:21.

17. Furtado LRI, Ávila MO, Fehlberg MFB, Teixeira MM, Rosado RLI, Martins LFS, et al. Prevalência e avaliação de fatores de risco à leptospirose canina no Município de Pelotas-RS. Arq Inst Biol 1997; 64:57-61.

18. Suárez-Hernández M, Bustelo-Aguila J, PerezGonzález L, Gorgoy-González V. Brote de leptospirosis em ninõs con predomínio meningoencefálico, en el município Móron. Rev Cubana Med Trop 1991; 43:136-9.

19. Mascolli R, Pinheiro SR, Vasconcelos AS, Ferreira F, Morais ZM, Pinto CO, et al. Inquérito sorológico para leptospirose em cães do Município de Santana de Parnaíba, São Paulo, utilizando a campanha de vacinação anti-rábica do ano de 1999. Arq Inst Biol 2002; 69:25-32.

20. Ávila MO, Furtado LRI, Teixeira MM, Rosado RLI, Martins LFS, Brod CS. Aglutininas antileptospíricas em cães na área de influência do centro de controle de zoonoses, Pelotas, RS, Brasil, ano de 1995. Ciênc Rural 1998; 28:107-10.

21. Silva HR, Tavares Neto J, Bina JC, Meyer R. Leptospirose-infecção e forma subclínica em crianças de Salvador, Bahia. Rev Soc Bras Med Trop 2003; 36:227-33.

22. Romero EC, Bernardo CC, Yasuda PH. Human leptospirosis: a twenty-nine year serological study in São Paulo, Brazil. Rev Inst Med Trop S Paulo 2003 ; 45:245-8.

23. Figueiredo CM, Mourão AC, Oliveira MA, Alves WR, Ooteman MC, Chamone CB, et al. Leptospirose humana no Município de Belo Horizonte, Minas Gerais, Brasil: uma abordagem geográfica. Rev Soc Bras Med Trop 2001; 34:331-8.

Recebido em 20/Abr/2005

Versão final reapresentada em 08/Jul/2005

Aprovado em 27/Jul/2005 